\title{
Mountain Pine Beetle Impacts on Vegetation and Carbon Stocks
}

\section{Background}

In the Southern Rocky Mountains, an epidemic outbreak of mountain pine beetle (Dendroctonus ponderosae; MPB) has caused levels of tree mortality unprecedented in recorded history (fig. 1). The impacts of this mortality on vegetation composition, forest structure, and carbon stocks have only recently received attention, although the impacts of other disturbances such as fires and land-use/land-cover change are much better known.

This study, initiated in 2010, aims to increase our understanding of MPB outbreaks and their impacts. We have integrated field-collected data with vegetation simulation models to assess and quantify how long-term patterns of vegetation and carbon stocks have and may change in response to MPB outbreaks and other disturbances.

\section{Research Objectives}

- Quantify changes in carbon storage and biogeochemical cycling in Southern Rocky Mountain forests in relation to MPB outbreak severity.

- Develop dynamic models to project how MPB outbreaks will affect long-term forest vegetation succession and structure and consequences for carbon storage.

- Compare the long-term impacts of MPB outbreaks to other disturbances (for example, wildfires).

- Develop remote sensing approaches for monitoring and assessing broad-scale impacts of MPB outbreaks on biogeochemical cycling.

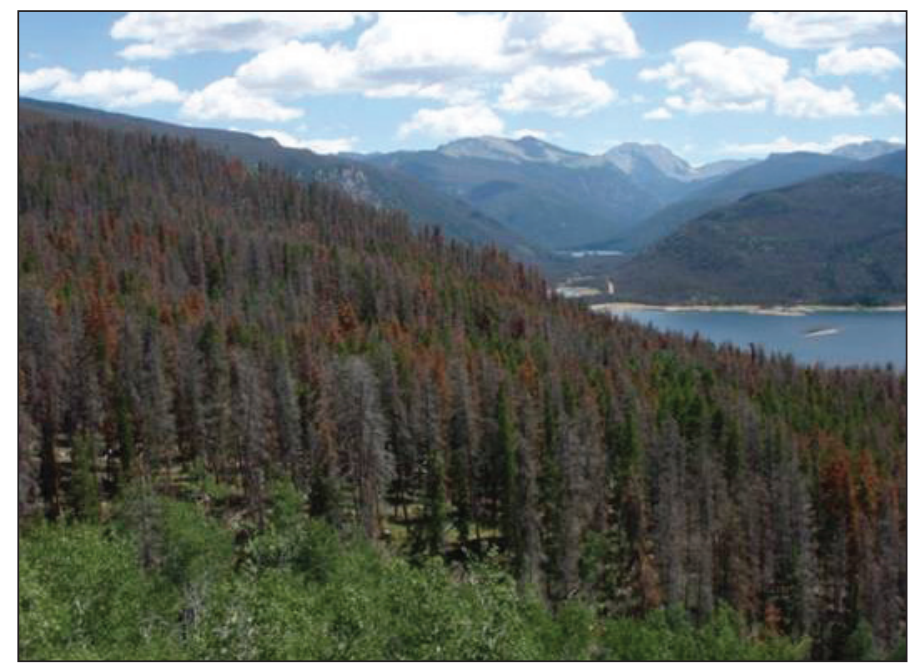

Figure 1. Mountain pine beetle-caused mortality in lodgepole pine forests near Grand Lake, Colorado, in 2008

\section{Approach}

To address the research objectives of this study, we used the following combination of field data, remotely sensed data, and ecological simulation models:

- Forest vegetation data collected at 119 plots located in eastern Grand County, Colorado (figs. 2 and 3). These data include individual species, status, size, and biomass for large trees, saplings, and seedlings, as well as downed woody debris, fuel loads, and understory vegetation.

- Light detection and ranging (LiDAR) data to monitor the extent and severity of the MPB outbreak and provide wall-towall input data on vegetation structure for modeling efforts.

- Tree-growth models to project changes in vegetation composition and structure, and carbon stocks following MPB outbreaks and other disturbances, such as wildfire, where the impacts are well understood and provide a reference point for comparison with MPB impacts.

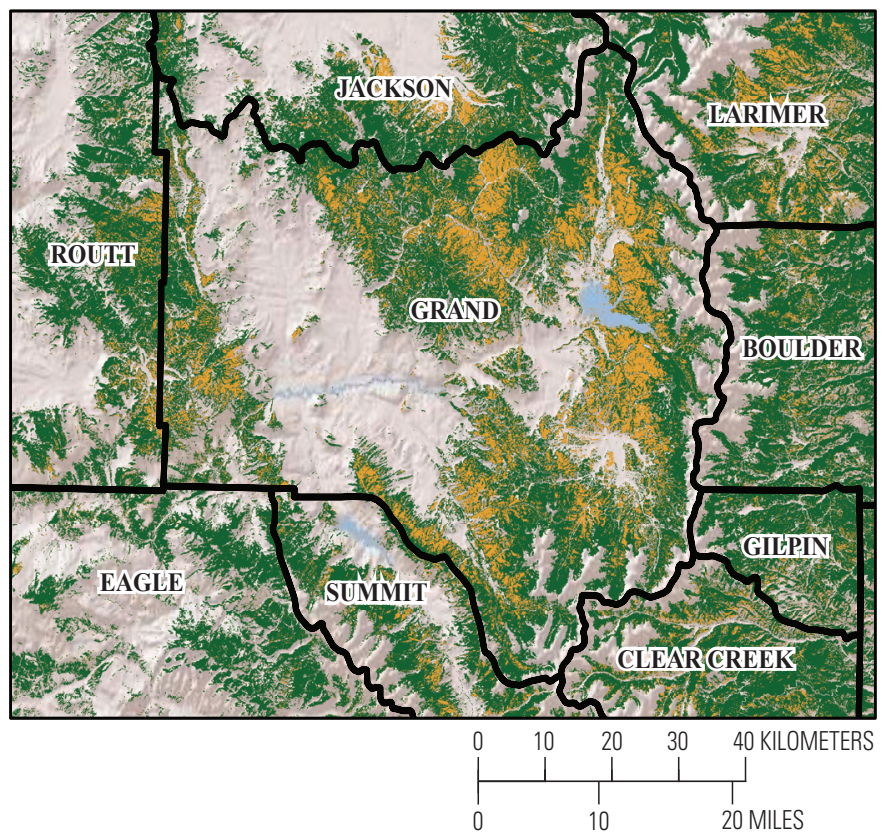

EXPLANATION

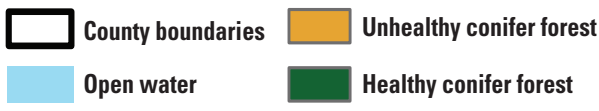

Figure 2. Subset of the Colorado Statewide conifer health map produced from 2009 Landsat imagery highlighting tree mortality in Grand County, Colorado. 


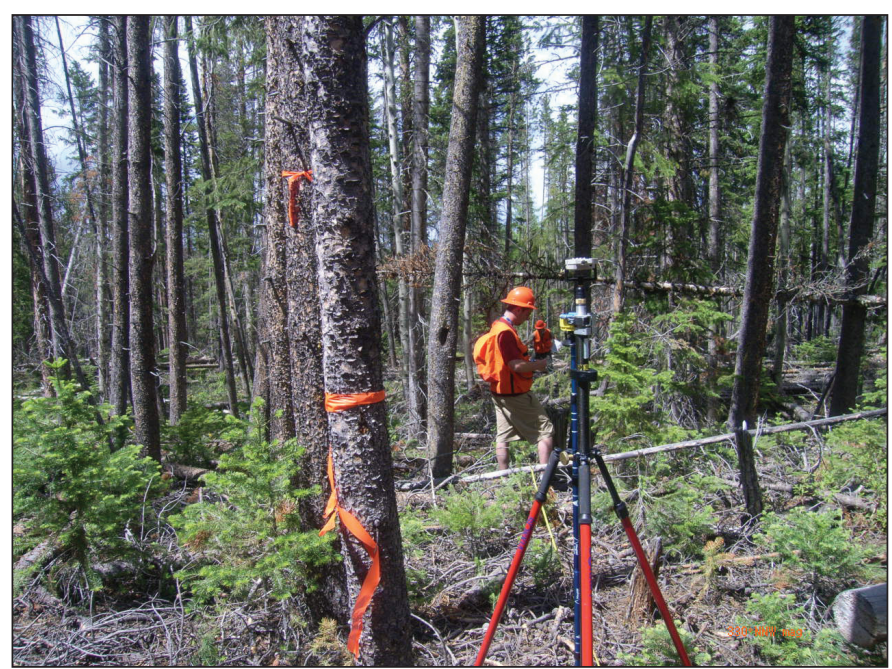

Figure 3. Field-data collection in mountain pine beetle-affected lodgepole pine forests in Grand County, Colorado.

\section{Findings}

- The MPB outbreak killed 65 percent of the lodgepole pine trees and 76 percent of lodgepole pine basal area.

- Carbon in the standing-live biomass pool was reduced by 80 percent and 97 percent after MPB and wildfire disturbances, respectively.

- Results of a 200-year forest-growth simulation suggest that basal area of lodgepole pine will return to predisturbance conditions 70 (MPB) and 80 (wildfire) years after disturbance.

- Simulated standing-live biomass returned to predisturbance levels as early as 40 and 50 years after the MPB epidemic and wildfire, respectively (fig. 4).

- Downed-dead biomass was projected to remain at higher levels than predisturbance conditions after both MPB disturbance and wildfire over the entire 200-year simulations.

\section{Publications and Presentations Resulting from this Study}

Caldwell, M.K., Hawbaker, T.J., Briggs, J.S., Cigan, P.W., and Stitt, S.C., 2013, Simulated impacts of mountain pine beetle and wildfire disturbances on forest vegetation composition and carbon stocks in the Southern Rocky Mountains: Biogeosciences, 10, 8203-8222, doi:10.5194/bg-10-8203-2013, available at $h t t p: / / w w w . b i o g e o s c i e n c e s . n e t / 10 / 8203 / 2013 /$ bg-10-8203-2013.html.

Caldwell, M.K., Hawbaker, T.J., Briggs J.S., 2012, Using FVS to model carbon and species composition trajectory changes resulting from disturbances: The 4th Vegetation Simulator Conference, Apr. 17-19, Fort Collins, Colo.

Caldwell, M.K., Hawbaker, T.J., Cigan, P.W., Stitt, S.C., Briggs, J.S., 2011, Changes in forest vegetation and carbon storage following mountain pine beetle disturbance in the Southern Rocky Mountains: Ecological Society of America 96th Annual Meeting, Aug. 7-12, Austin, Tex.

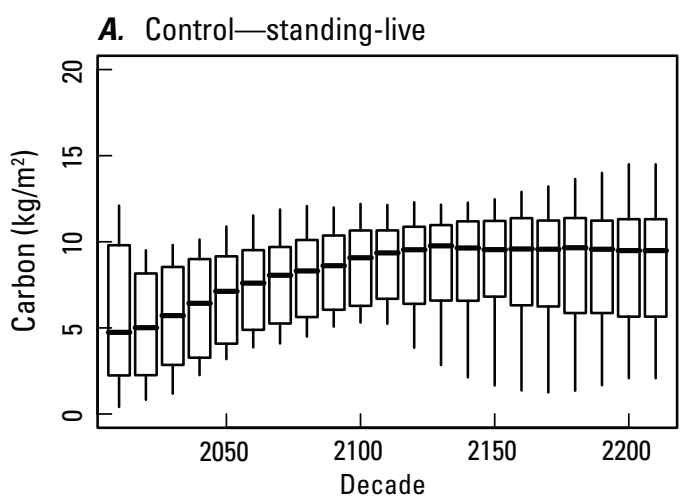

B. MPB-standing-live

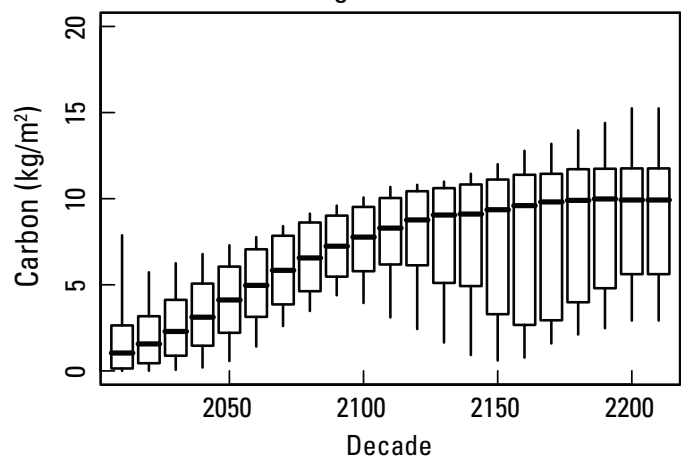

C. Fire-standing-live

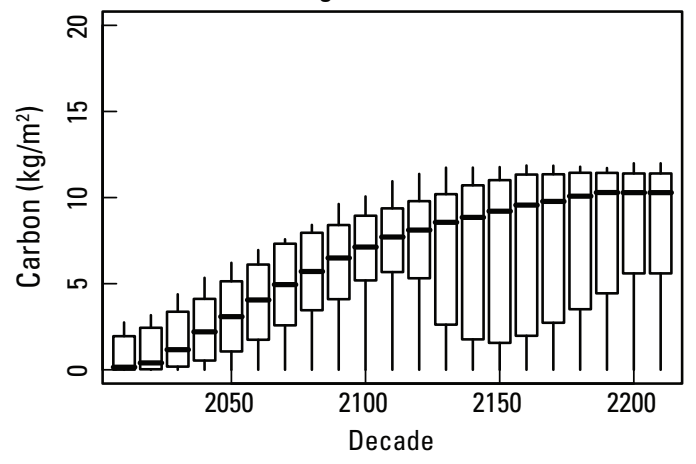

EXPLANATION

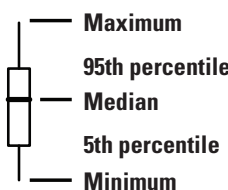

Figure 4. Boxplots of standing-live carbon stored in forests during a simulation period from 2010 to 2210 for conditions that were $(A)$ undisturbed ("control"), $(B)$ disturbed by an actual mountain pine beetle (MPB) epidemic, and $(C)$ affected by a simulated severe wildfire. Whiskers span 100th to 95th and 0 to 5th percentiles, boxes span 95th to 5th percentile, and horizontal lines show median values of carbon for each decade of the simulation period. $\mathrm{kg} / \mathrm{m}^{2}$, kilograms per square meter.

Todd J. Hawbaker, Jennifer S. Briggs, Megan K. Caldwell, and Susan Stitt

U.S. Geological Survey

Geosciences and Environmental Change Science Center, Denver, Colorado

Contact: tjhawbaker@usgs.gov,303-236-1371 